\title{
Evaluación de factores de riesgo en las Estaciones con Arte Rupestre de la provincia de Málaga
}

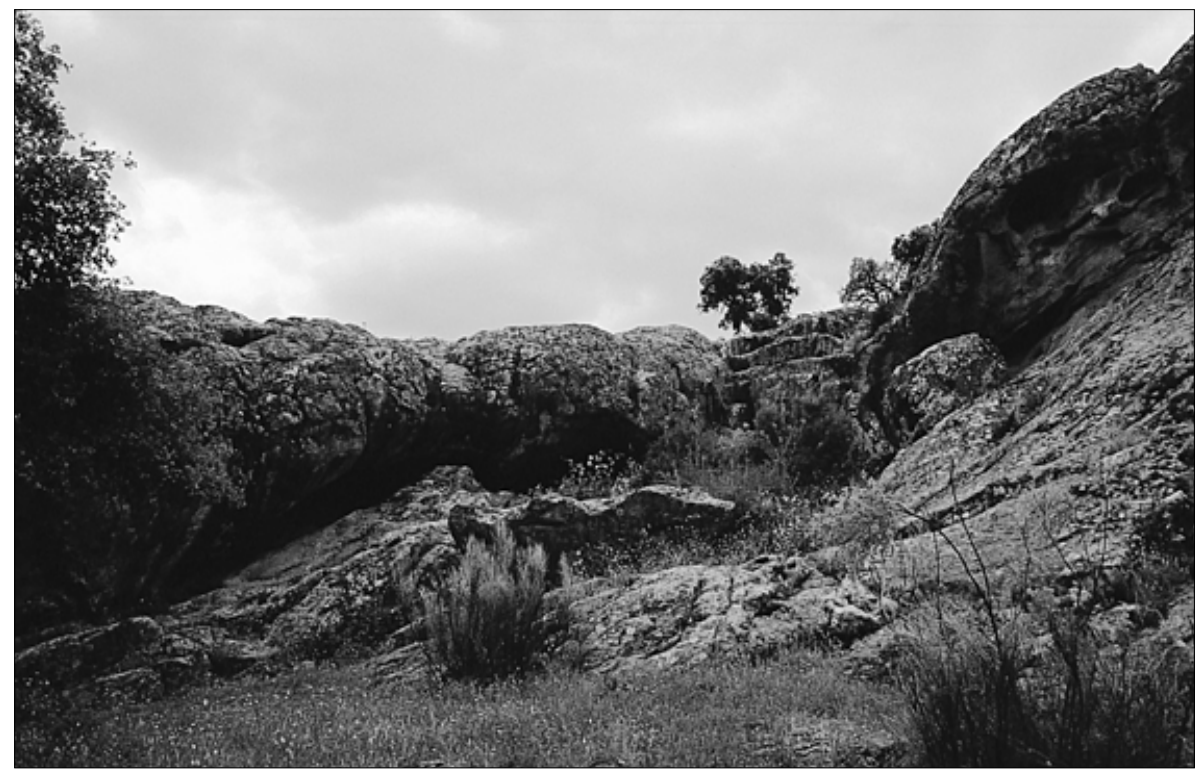

Isabel Santana Falcón

Arqueóloga

\section{Resumen}

Se explica la metodología y, parcialmente, los resultados de un trabajo realizado por encargo de la Dirección General de Bienes Culturales de la Consejería de Cultura de la Junta de Andalucía para determinar los posibles riesgos de deterioro de las estaciones con arte rupestre no incluidas en espacios naturales protegidos de las provincias de Málaga, Jaén y Cádiz.

Palabras clave

Arte rupestre / Paleolítico / Postpaleolítico / Protección / Conservación / Málaga
En diciembre de 1997 la Consejería de Cultura, desde el Servicio de Protección del Patrimonio Histórico de la Dirección General de Bienes Culturales, me adjudicó mediante concurso para la contratación de consultoría y asistencia técnica el encargo denominado Delimitación de áreas con riesgo de destrucción en las estaciones con arte rupestre de Andalucía. Los trabajos correspondientes a la provincia de Málaga se llevaron a cabo durante los años 1998 y 1999 , contando con mi dedicación a tiempo completo y la colaboración de otros dos arqueólogos ' y otros profesionales (Arquitecto, Geógrafo, Abogado e Informáticos), que fueron preguntados sobre aspectos puntuales de la documentación técnica, gráfica o cartográfica que debimos manejar, analizar y procesar².

Un trabajo de esta índole, destinado a planificar la gestión administrativa, debía considerar las estaciones con arte rupestre principalmente desde su pertenencia al conjunto de bienes del Patrimonio Histó- 
rico -no debemos olvidar que estos yacimientos arqueológicos están declarados Bien de Interés Cultural por ministerio de la Ley 16/1985 del Patrimonio Histórico Español (art. 40.2)-y, por lo tanto, no primar ninguna de las líneas de actuación en la tutela de los bienes patrimoniales, a saber: Protección, Conservación, Investigación y Difusión 3 . Más bien era necesario acometer el análisis del estado actual de las cuevas y abrigos con manifestaciones artísticas rupestres desde una óptica global, que integrara cada uno de aquellos aspectos por sí mismos y luego estableciera las correspondientes, y necesarias, relaciones entre lo que hasta ahora se ha hecho y lo que sería preciso abordar, y priorizar, en el futuro.

Partiendo de estas premisas logramos construir un exhaustivo documento del que ahora sólo vamos a explicar el método de trabajo utilizado y avanzar algunas conclusiones, a nivel general, con respecto a las estaciones con arte rupestre de la provincia de Málaga.

\section{Metodología}

En mi opinión, el éxito de un trabajo de estas características depende en gran medida de una exhaustiva recopilación de cualquier información relacionada con el bien objeto de estudio, de manera que obtengamos una visión general de todos aquellos elementos y/o situaciones que de algún modo, aunque inicialmente no podamos entender cómo, afecten al área donde se encuentra el yacimiento arqueológico. Partiendo de esta premisa consultamos los archivos de aquellas administraciones y organismos cuyas competencias incluyen el control de actuaciones y actividades sobre el territorio y, por supuesto, sobre los bienes del Patrimonio Histórico.

De la Consejería de Cultura, los archivos de los Servicios de Protección, Conservación e Investigación y Difusión del Patrimonio Histórico de la Dirección General de Bienes Culturales; del Centro de Documentación del Instituto Andaluz del Patrimonio Histórico, la base de datos del Sistema de Información del Patrimonio Histórico de Andalucía (S.I.P.H.A.), de la cual obtuvimos el listado de estaciones con arte rupestre sobre el que debíamos trabajar; de la Delegación Provincial en Málaga de la Consejería de Cultura, documentación diversa del Departamento de Protección del Patrimonio Histórico.

De otras administraciones: la Consejería de Medio Ambiente de la Junta de Andalucía nos proporcionó el Sistema de Información Ambiental de Andalucía (SINAMBA), una fuente documental que se nos reveló muy útil no sólo para conocer distintos aspectos del territorio estudiado sino también como instrumento gráfico; el Departamento de Protección del Medio Ambiente del Servicio de Estructuras de la Delegación Provincial en Málaga de la Consejería de Medio Ambiente nos facilitó información diversa acerca de los espacios naturales gestionados directamente por la propia Consejería, con su correspondiente cartografía básica; el Servicio citado también nos proporcionó la Orden General de Vedas vigente durante 1998-1999.

Técnicos de la Dirección General de Urbanismo de la Consejería de Obras Públicas y Transportes nos facilitaron el acceso a los documentos urbanísticos, asesorándonos acerca de aspectos concretos de la documentación, sobre todo en el ámbito procedimental y de estado actual de los expedientes. En el Servicio de Ordenación del Territorio y Urbanismo de la Delegación Provincial en Málaga de la Consejería de Obras Públicas consultamos la gran mayoría de la documentación urbanística, permitiéndonos reproducir aquella documentación cartográfica y textual que consideramos necesario mantener en nuestro poder.

Asimismo, el Servicio de Vías y Obras del Área de Infraestructuras, Obras y Urbanismo de la Diputación de Málaga nos remitió un listado de los proyectos que ese área ha ejecutado o está llevando a cabo en estos momentos en los municipios donde se encuentran las estaciones con arte rupestre.

Por último, el Catastro de Rústica de la Delegación Provincial de Hacienda de Málaga nos remitió la información catastral de los terrenos que consideramos afectados por la ubicación de las estaciones con arte rupestre.

En cualquier caso queremos dejar constancia de la colaboración de todas las personas que amablemente nos atendieron, principalmente técnicos de las administraciones enumeradas, que mostraron gran interés por el trabajo que desarrollábamos. (Fig. I)

También realizamos numerosas salidas para localizar y visitar las estaciones con arte rupestre -enumeradas en la Figura I-. En todos los casos la ubicación de los yacimientos arqueológicos se llevó a cabo mediante un GPS lo cual nos permitió identificarlos con detalle en la cartografía.

Asimismo, la revisión de la bibliografía y documentación de carácter científico y técnico relacionada con estos enclaves arqueológicos - la relativa tanto a las propias cuevas y abrigos como a los asentamientos que se sitúan dentro de las cavidades o en sus inmediaciones- nos permitió llegar a algunas conclusiones sobre el estado actual de la investigación del arte rupestre prehistórico malagueño y sus consecuencias en la tutela de estos bienes patrimoniales, a saber:

- Una reproducción de las pinturas rupestres del Abrigo del Cortijo de La Escardadera, en el Término Municipal de Archidona, fue publicada a principios de los años $90,{ }^{4}$ y este mismo abrigo se cita también en el Catálogo de yacimientos con pinturas rupestres en Andalucía ${ }^{5}$. Sin embargo, no aparecía incorporado en el planeamiento urbanístico municipal; es más, el documento de Revisión de las Normas Subsidiarias de Archidona, presentado en abril de 1999, tampoco lo recogía, limitándose a repetir las delimitaciones y determinaciones recogidas en el documento anterior, aprobado provisionalmente en 1988. 


\section{Fig. 1. Estaciones con arte rupestre de la provincia de Málaga recogidas en el SIPHA y normativa urbanística que las afecta}

\begin{tabular}{|c|c|}
\hline ABRIGOS 1-2. TAJOS DEL VILO & $\begin{array}{l}\text { Plan Especial de Protección del Medio Físico. Málaga. } \\
\text { Complejo Serrano de Interés Ambiental Altos de Alfarnatejo-Alhama } \\
\text { Normas Subsidiarias de Planeamiento. Alfarnatejo }\end{array}$ \\
\hline $\begin{array}{l}\text { ABRIGOS 20, } 25,58 \text { Y 59. VENTA DEL FRAILE } \\
\text { ABRIGOS 1-4. CORTIJO DE CHIRINO } \\
\text { ABRIGO DEL CERRO DE LOS TRÉBEDESP.E.P.M.F. }\end{array}$ & $\begin{array}{l}\text { Área deProtección cautelar Montes de Málaga y Axarquía } \\
\text { Normas Subsidiarias de Planeamiento. Almogía }\end{array}$ \\
\hline CUEVA DE LOS CHIVOS & $\begin{array}{l}\text { P.E.P.M.F. Complejo Serrano de Interés Ambiental Sierras de } \\
\text { Camarolos-Las Cabras } \\
\text { Plan General Municipal de Ordenación Urbana. Antequera }\end{array}$ \\
\hline $\begin{array}{l}\text { ABRIGO DEL CORTIJO DE LA ESCARDADERA } \\
\text { CUEVA DE LAS GRAJAS }\end{array}$ & $\begin{array}{l}\text { P.E.P.M.F. C. S. I. A. Sierra de Archidona } \\
\text { Normas Subsidiarias de Planeamiento. Archidona }\end{array}$ \\
\hline CUEVA DE DOÑA TRINIDAD & $\begin{array}{l}\text { P.E.P.M.F. Espacio Forestal Interés Recreativo Sierra de La Pizarra } \\
\text { Normas Subsidiarias de Planeamiento. Ardales }\end{array}$ \\
\hline CUEVA DEL TORO 0 CALAMORRO & $\begin{array}{l}\text { P.E.P.M.F. C. S. I. A. Sierra de Mijas } \\
\text { Plan General Municipal de Ordenación Urbana. Benalmádena }\end{array}$ \\
\hline SIMA DE DOÑA CURRA O LOS MURCIÉLAGOS & P.E.P.M.F. C. S. I. A. Sierras Prieta-Cabrilla-Alcaparaín \\
\hline ABRIGOS 1-22 Y 41 DE PEÑAS DE CABRERA & $\begin{array}{l}\text { P.E.P.M.F. Área de Protección cautelar Montes de Málaga y Axarquía } \\
\text { Normas Subsidiarias de Planeamiento.Casabermeja }\end{array}$ \\
\hline RAJA DEL RETUNTÚN & $\begin{array}{l}\text { P.E.P.M.F. C. S. I. A. Sierras Prieta-Cabrilla-Alcaparaín } \\
\text { Normas Subsidiarias de Planeamiento. Casarabonela }\end{array}$ \\
\hline $\begin{array}{l}\text { CUEVA NAVARRO } \\
\text { CERRO DE LA TORTUGA }\end{array}$ & Plan General de Ordenación Urbana. Málaga \\
\hline CUEVA DE PECHO REDONDO 0 DELA TORRECILLA & $\begin{array}{l}\text { P.E.P.M.F. C. S. I. A. Sierras Blanca-Canuta-Alpujata } \\
\text { Plan General de Ordenación Urbana. Marbella }\end{array}$ \\
\hline CUEVA DE LOS PORQUEROS & $\begin{array}{l}\text { P.E.P.M.F. C. S. I. A. Sierras Camorra - Mollina } \\
\text { Normas Subsidiarias de Planeamiento. Mollina }\end{array}$ \\
\hline CUEVA DE MONTEJAQUE O DEL HUNDIDERO & $\begin{array}{l}\text { P.E.P.M.F. Paraje Sobresaliente Cueva del Hundidero. Cerro Tavizna } \\
\text { Plan de Uso y Protección. Parque Natural de la Sierra de Grazalema }\end{array}$ \\
\hline CUEVA DE NERJA & $\begin{array}{l}\text { P.E.P.M.F. Yacimiento de Interés Cientf́fico Cueva de Nerja P.O.R.N. } \\
\text { Parque Natural de las Sierras de Alhama, Tejeda y Almijara. } \\
\text { Plan General Municipal de Ordenación Urbana. Nerja. } \\
\text { Monumento Histórico-Artístico. Decreto de } 25 \text { de marzo de } 1961 .\end{array}$ \\
\hline ABRIGO DE MARCHAMONAS & $\begin{array}{l}\text { P.E.P.M.F. C. S. I. A. Altos de Alfarnatejo-Alhama } \\
\text { Normas Subsidiarias de Planeamiento. Periana }\end{array}$ \\
\hline CUEVAS DEL HIGUERÓN Y DE LA VICTORIA & Plan General de Ordenación Urbana. Rincón de la Victoria \\
\hline ABRIGO DEL PUERTO DEL VIENTO & $\begin{array}{l}\text { P.E.P.M.F. C. S. I. A. Sierras Oreganal-Hidalga-Blanquilla } \\
\text { Plan General Municipal de Ordenación Urbana . Ronda }\end{array}$ \\
\hline CUEVA DEL TAJO DEL MOLINO & $\begin{array}{l}\text { P.E.P.M.F. C. S. I. A. Sierra de Peñarrubia } \\
\text { Normas Subsidiarias de Planeamiento. Teba }\end{array}$ \\
\hline ABRIGOS DE CAMAROLOS 1 Y 2 & $\begin{array}{l}\text { P.E.P.M.F. Málaga. C. S. I. A. Sierras de Camarolos-Las Cabras } \\
\text { Normas Subsidiarias de Planeamiento. Villanueva del Rosario }\end{array}$ \\
\hline
\end{tabular}


- Advertimos de la existencia de otras estaciones con arte rupestre en la comarca, a saber: Sopalmito, Peña de los Enamorados y conjunto de Malnombre, citadas como" en estudio" en la publicación de V. E. M. Vivas ${ }^{6}$. Con las noticias y las indicaciones publicadas no fue posible localizarlos.

- En la Sierra de Camarolos, que se extiende por los Términos de Villanueva del Rosario y Antequera, la Consejería de Cultura conocía la existencia de los abrigos I y II7; aún así la bibliografía enumera otras estaciones con arte rupestre en el lugar ${ }^{8}$, de los que tampoco encontramos datos más o menos concretos acerca de su emplazamiento. Como en el caso de Archidona, las únicas estaciones con arte rupestre citadas en el planeamiento urbanístico son los abrigos I y II, aunque las Normas Subsidiarias fueron aprobadas con posterioridad al descubrimiento de todos estos yacimientos.

- Según se dice en las Normas Subsidiarias de Almogía, Anexo, p. 5, con respecto al Conjunto Rupestre de Chirino: ... se hace necesario un estudio urgente que lo documente gráficamente, estudio para el que se ha solicitado el correspondiente permiso de urgencia de la Delegación Provincial de Cultura de la Junta de Andalucía. No obstante, no encontramos ningún informe o publicación que contenga los resultados del trabajo que se anunciaba.

- El complejo cárstico Hundidero-Gato, que se extiende por los Términos Municipales de Montejaque y Benaoján, ofrece, al parecer, otros restos pictóricos, además de los ya citados en la bibliografía más antigua, que han sido estudiados en los últimos años 9 .

La revisión bibliográfica ha sido también fundamental para recolectar otros documentos gráficos, dispersos en sus correspondientes expedientes y/o en publicaciones varias. La recopilación de esa información interesaba al trabajo por dos cuestiones fundamentales: permitía unificar en una base de datos informatizada la documentación gráfica y cartográfica, integrándola con los datos textuales y documentales; por otra parte, ha sido de gran importancia contar con las plantas, y a veces secciones, de casi todas las cuevas y abrigos en el momento de redactar las determinaciones de protección para los yacimientos. Hemos de advertir que las plantas generales de las grandes cuevas fueron tomadas de la bibliografía al uso, por lo que no siempre debemos considerarlas exhaustivas en su representación y en cuanto a la información que ofrecen, aunque las cuevas del Higuerón-Suizo y de la Victoria (Rincón de la Victoria) y el Conjunto Rupestre de las Peñas de Cabrera (Casabermeja) cuentan con buenos levantamientos topográficos realizados por encargo de la Dirección General de Bienes Culturales.

En general, excepto para los abrigos con pinturas de Almogía, Ronda y Villanueva del Rosario, aportamos información de estas características sobre el resto de las cavidades de la provincia de Málaga. En Almogía las pinturas prehistóricas aún no han sido documen- tadas; en Villanueva del Rosario, como explicamos más arriba, aún están en estudio; y no encontramos ninguna noticia con respecto a las manifestaciones artísticas que alberga el Abrigo del Tajo del Viento en Ronda, que sólo aparece citado en el Catálogo... elaborado por M. Más Cornellá en 1994.

Una vez obtenida la información y visitados los emplazamientos de cuevas y abrigos, estudiamos la información urbanística, examinando los Planes Generales de Ordenación Urbana de los Municipios de Antequera, Benalmádena, Málaga, Marbella, Nerja, Rincón de la Victoria y Ronda, y las Normas Subsidiarias de los Términos Municipales de Alfarnatejo, Almogía, Archidona, Ardales, Casabermeja, Casarabonela, Mollina, Periana, Teba y Villanueva del Rosario.

Las localidades de Benaoján, Carratraca y Montejaque no contaban con figuras de planeamiento propias, por lo que deberían regirse según la normativa de planeamiento provincial pero no existe un documento de estas características para Málaga. Por suerte, en estos casos el arte rupestre se halla en espacios naturales protegidos: Parque Natural de la Sierra de Grazalema (cuevas de La Pileta y Hundidero-Gato, en Benaoján y Montejaque respectivamente); y Complejo Serrano de Interés Ambiental Sierras Prieta-Cabrillas-Alcaparaín (Sima de la Curra o de los Murciélagos, en Carratraca), estando por lo tanto sujetas a las determinaciones del Plan Especial de Protección del Medio Físico de la Provincia de Málaga y al Plan de Uso y Protección de la Sierra de Grazalema. En realidad, la gran mayoría de las cavidades tratadas se encuentran en áreas protegidas en el Plan Especial de Protección del Medio Físico de la Provincia de Málaga, por lo que también debimos analizar y valorar este documento.

La cartografía que acompaña al trabajo fue elaborada desde los Mapas Topográficos de Andalucía E. I: 10.000 que edita en CDROM la Consejería de Obras Públicas y Transportes de la Junta de Andalucía. El sistema de representación digital ofrece algunas ventajas: la ubicación de las coordenadas es casi perfecta, desechándose los errores que puedan tener lugar con el dibujo a mano alzada; y los planos pueden escalarse y fraccionarse a voluntad, lo que proporciona mayor facilidad para su presentación y lectura.

Al igual que la planimetría, también fueron digitalizadas y tratadas las fotografías tomadas en las visitas que realizamos a las estaciones con arte rupestre. Todas las imágenes se almacenaron en formatos TIFF y JPEG, por su gran compatibilidad.

\section{El Documento}

El resultado del trabajo lo presentamos en cinco tomos denominados Determinación de áreas con riesgo de destrucción en el ámbito de las estaciones con Arte Rupestre de Andalucía. Málaga. Cada volumen consta de la siguiente información: 
Tomo I. C.E.A.R.A.

Catálogo de Estaciones con Arte Rupestre en Andalucía.

Recoge los formularios de identificación de las cuevas y abrigos con arte rupestre. La información se individualiza para cada uno de los yacimientos arqueológicos, excepto en las Peñas de Cabrera, un conjunto de 23 abrigos con pinturas rupestres esquemáticas ubicados en un cerro y que mantienen una clara unidad temática, técnica, estilística y, consiguientemente, cultural; los Abrigos I y 2 de los Tajos del Vilo, en Alfarnatejo; los Abrigos 20, 25, 58 y 59 de la Venta del Fraile y los Abrigos 1,2,3 y 4 de Chirino, en Almogía, todos en las mismas circunstancias.

Las fichas, diseñadas específicamente para el Catálogo... aunque mantienen los campos del Sistema de Información del Patrimonio Histórico de Andalucía (S.I.P.H.A.), registran toda la información obtenida sobre cada yacimiento. Poseen un número de orden con relación a su posición y respecto a las páginas de que consta cada una; en algunos casos introdujimos páginas complementarias, identificadas con el número de orden de la página a la que continúan, añadiéndole la letra A. Para componer el documento preferimos el orden alfabético porque parece el más fácil de seguir para el lector que no conozca con detalle las provincias.

La información que ofrece el Catálogo..., dividida a partir de los diferentes bloques de acción en que administrativamente se ha distinguido la gestión del Patrimonio Histórico, presenta algunas diferencias con respecto a los inventarios realizados con anterioridad; quizás una de las más destacables es que parte de una localización y ubicación más detallada de los yacimientos. Para completar con rigor nuestro trabajo también resultaba imprescindible describir con la mayor exactitud los bienes y elementos que se pretende proteger, así como su estado de conservación; para ello, además de usar la información textual, recurrimos a la documentación cartográfica, planimétrica y gráfica, a las cuales dedicamos distintos apartados dentro del corpus general de información. Asimismo, siendo el motivo principal del trabajo la determinación de factores de riesgo y su incidencia en las estaciones con arte rupestre, ideamos los formularios II y |2, que se explican a continuación.

Por último, debemos recordar que los datos referidos a la propiedad y propietarios del suelo se revelaron de gran interés a la hora de sugerir posibles actuaciones, además de ser una información imprescindible para la confección de expedientes de protección.

Los formularios que constituyen el C.E.A.R.A. constan de los siguientes campos:

I.I. Identificación del Yacimiento Arqueológico: Localización; Denominación; $N^{\circ}$ de Inventario en el S.I.P.H.A., Clasificación cultural; Información carto- gráfica; Tipología; Accesos y emplazamiento; Ruta - mediante coordenadas UTM se indican uno o varios puntos del acceso más fácil-; Propiedad y propietarios.

1.2. Descripción: Datos relacionados con la tipología y características del abrigo o cueva, así como los referidos al medio natural y a otros yacimientos arqueológicos culturalmente sincrónicos que se encuentren en sus inmediaciones.

1.3. Investigación: Actuaciones realizadas sobre el yacimiento, incluyendo fechas y director del proyecto. Bibliografía actualizada hasta 1998.

I.4. Información Gráfica: Planimetría: plantas y secciones de las cavidades, obtenidas en los archivos de esa Consejería y a partir de la bibliografía científica al uso. Las fotografías fueron tomadas en nuestras visitas a los yacimientos.

1.5. Estado de Conservación: Basándonos en los datos aportados por la bibliografía especializada y en nuestro conocimiento de los sitios arqueológicos, describimos el estado de conservación de las pinturas y las medidas de conservación adoptadas. Al mismo tiempo proponemos la adopción de medidas preventivas y, finalmente, exponemos nuestra impresión sobre el estado de la cavidad cuando la visitamos; cuando existen valoraciones de expertos en este sentido, éstas se reseñan íntegramente.

1.6. Protección Legal y Administrativa: Especificamos la figura de protección vigente y proponemos aquella que, a la vista del estado actual del bien patrimonial y de las presiones que soporta o previsiblemente soportará, nos parece más conveniente desarrollar, razonando brevemente la estrategia de nuestra propuesta y describiendo de igual modo el ámbito de protección sugerido, el cual también se muestra gráficamente.

I.7-I.I0. Planeamiento Urbanístico (I-IV): Recogen tanto las determinaciones del planeamiento urbanístico, como cualesquiera otras disposiciones sectoriales que incidan sobre el territorio donde se encuentra el sitio arqueológico (Plan Especial de Protección del Medio Físico, normativa sobre espacios naturales protegidos...).

I.I I. Factores de Riesgo Esenciales: Analizamos los diferentes hechos, antrópicos y naturales, que, a nuestro entender, pueden incidir, o están incidiendo, negativamente en la preservación del yacimiento arqueológico.

I.12. Factores de Riesgo Externos: Se especifican los proyectos de intervención en el territorio que podrían representar peligro de deterioro para el yacimiento, así como el tipo de afección que suponen. (Fig. 2) 
Fig. 2. Definición de los Grados de Riesgo.

\begin{tabular}{|c|c|}
\hline NULO & $\begin{array}{l}\text { No se puede inferir, en las circunstancias actuales y/o según las carácterís- } \\
\text { ticas de la actuación que se está ejecutando, la existencia de algún peligro } \\
\text { para la integridad del yacimiento arqueológico. }\end{array}$ \\
\hline MÍNIMO & $\begin{array}{l}\text { Existe alguna posibilidad de riesgo para una correcta conservación del ya- } \\
\text { cimiento arqueológico, pero en las circunstancias actuales y/o a tenor de } \\
\text { las características de la actuación que se propone o se está ejecutando, éste } \\
\text { no es un elemento determinante en el grado de deterioro del mismo, ni pa- } \\
\text { rece que pueda serlo en un futuro inmediato (p. ej. labores agrícolas en tor- } \\
\text { no a algunas estaciones con arte rupestre; vandalismo y/o expolio en grutas } \\
\text { abiertas a la visita turística organizada, etc.) }\end{array}$ \\
\hline SOPORTABLE & $\begin{array}{l}\text { Se trata de un factor de deterioro conocido y de consecuencias previsibles } \\
\text { cuya incidencia sobre el yacimiento arqueológico es intrínseca al mismo, o } \\
\text { está en íntima relación con su morfología, o bien es el resultado insepara- } \\
\text { ble de la ejecución de un proyecto en el que convergen o priman otros inte- } \\
\text { reses diferentes a la preservación del yacimiento arqueológico. Sin embar- } \\
\text { go, estos efectos negativos pueden ser reconducidos hasta niveles mínimos } \\
\text { en cuanto a su acción sobre el sitio arqueológico (p. ej. los factores meteo- } \\
\text { rológicos; el uso actual de algunas cuevas y abrigos con arte rupestre; al- } \\
\text { gunos proyectos de obra pública o explotaciones agrícolas e industriales } \\
\text { que no afectan directamente al yacimiento arqueológico, sino que tienen lu- } \\
\text { gar en sus inmediaciones). }\end{array}$ \\
\hline SOSTENIBLE & $\begin{array}{l}\text { Algunos proyectos de intervención sobre el territorio, incluso los destina- } \\
\text { dos a su explotación turístico-cultural o a poner en valor un yacimiento ar- } \\
\text { queológico, pueden tener consecuencias negativas o indeseables para la } \\
\text { correcta conservación de los bienes patrimoniales sobre los que se preten- } \\
\text { de actuar. Es posible subvertir esta tendencia adoptando medidas preventi- } \\
\text { vas de protección e introduciendo en el proyecto modificaciones que permi- } \\
\text { tan minimizar el perjuicio y, en ocasiones, obtener beneficios de otra índole } \\
\text { que reviertan igualmente en la preservación del sitio arqueológico. Por } \\
\text { ejemplo, el acondicionamiento de una estación con arte rupestre para la vi- } \\
\text { sita organizada -queremos decir el diseño de un proyecto global para expo- } \\
\text { ner estos bienes patrimoniales, por lo que no debemos fijarnos en los yaci- } \\
\text { mientos arqueológicos de estas características que actualmente están } \\
\text { abiertos a la visita turística en la provincia de Málaga-; el desarrollo de pro- } \\
\text { yecto de "ecoturismo" o de "turismo cultural"; o la propia ejecución de al- } \\
\text { gunas actuaciones de conservación. }\end{array}$ \\
\hline INSOPORTABLE & $\begin{array}{l}\text { Las condiciones en que se encuentra actualmente el yacimiento arqueológi- } \\
\mathrm{co,} 0 \text { la ejecución del proyecto que se está realizando, conducirán a la des- } \\
\text { trucción de las manifestaciones artísticas parietales y/o de los niveles de } \\
\text { ocupación, o bien acelerarán de manera irreversible su deterioro ( } \mathrm{p} \text {. ej. mo- } \\
\text { vimientos de tierra incontrolados ocasionados por la explotación del terre- } \\
\text { no o encaminados al expolio del Patrimonio Arqueológico; pinturas y gra- } \\
\text { bados parietales directamente sometidos a la acción de los elementos; } \\
\text { insolación, Iluvia... y/o la acción de algunos animales; explotación turística } \\
\text { indiscrimidada). }\end{array}$ \\
\hline
\end{tabular}

\section{Tomo 2.}

Cartografia.

Creímos necesario que las representaciones cartográficas atendieran cuatro aspectos básicos: accesos y ubicación de los yacimientos; usos y aprovechamientos del suelo; protección legal y protección urbanística; delimitación del sitio arqueológico y del entorno de protección asignado. La operatividad en el manejo de la información aconsejaba reducir al máximo el número de planos, por lo que dependiendo de la complejidad de los usos del territorio y de las características de los sitios arqueológicos, ofrecemos:
- la ubicación del yacimiento con relación a la población de entidad más cercana

- un detalle del emplazamiento de la cueva o abrigo. Algunas veces se recogen también otros yacimientos que se encuentran en sus inmediaciones y que podríamos relacionar con aquéllas; en ese caso partimos de la información bibliográfica, por lo que no reflejamos su extensión y/o distribución espacial, ni nos pronunciamos acerca del grado de validez actual de esos datos.

- cuando el bien cuenta con una delimitación previa que le otorga algún grado de protección legal y/o 
urbanística, este ámbito se reseña igualmente. Se recoge, por ejemplo, la delimitación de los montes públicos en lo que afecta al sitio en cuestión y a los yacimientos que se hubieran detectado en sus inmediaciones, si se diera el caso.

- finalmente, se representa la delimitación que proponemos para la cueva o abrigo. Cuando contamos con información suficiente diferenciamos la delimitación del bien propiamente dicho del ámbito que, a nuestro entender, debe considerarse como entorno de protección. Las escalas empleadas fluctúan entre 1:20.000 y el 1:5.000 y los formatos, un A-3 ampliado a lo largo, fueron pensados para que las copias en papel pudieran consultarse y almacenarse con comodidad.

Se reproducen también las plantas y secciones de las grandes cuevas, a una escala de mayor detalle que la que, por cuestiones de facilidad en el manejo de la información, era aconsejable incluir en el Catálogo..., y se aportaron copias digitalizadas de las fotografías aéreas de algunas cavidades donde era importante reflejar esta información.

Tomo 3. Vol I.

Análisis urbanístico.

Dedicado al análisis y valoración de la documentación urbanística que afecta a las estaciones con arte rupestre. Estudiamos siete Planes Generales Municipales de Ordenación Urbana y diez Normas Subsidiarias Municipales, correspondientes a las diecisiete poblaciones donde se han localizado estos yacimientos. Sólo tres localidades no poseen figuras de planeamiento específicas, pero en estos casos, al igual que en los Municipios que cuentan con alguna figura de ordenación urbanística, las cavidades se hallan en espacios naturales protegidos, por lo que debimos incluir también la normativa medioambiental referente a aquellos ámbitos territoriales.

El análisis del planeamiento se llevó a cabo desde la selección de todos los aspectos normativos que afectan, o previsiblemente pudieran afectar, a las estaciones con arte rupestre en los Planes Generales de Ordenación Urbana, Normas Subsidiarias de Planeamiento, en el Plan Especial de Protección del Medio Físico de la Provincia de Málaga, en el Plan de Uso y Protección de la Sierra de Grazalema, en el Plan de Ordenación de Recursos Naturales de los Montes de Málaga y en el Plan de Ordenación de Recursos Naturales del Parque Natural de las Sierras de Alhama, Tejeda y Almijara. También estudiamos otros documentos de carácter territorial que pudieran albergar información de utilidad, como el Plan de Medio Ambiente de Andalucía (1995-2000) y las Bases para la ordenación del Territorio de Andalucía.

En relación con los ámbitos de protección definidos en el planeamiento planteamos nuevas propuestas, las cuales muestran sensibles diferencias. En realidad, excepto para los casos de la Cueva de La Pileta (Benaoján) y el Cerro de la Tortuga (Málaga), que ya contaban con expedientes de declaración como Zona Arqueológica Bien de Interés Cultural, en el resto de los enclaves con arte rupestre sólo coincidimos, y no siempre, con su ubicación -que debemos distinguir de la delimitación del bien propiamente dicha-, ya que la delimitación de los yacimientos en esos casos no va más allá del grafiado de un círculo alrededor de la cueva o abrigo, en el mejor de los casos. Así, fue necesario establecer distintas categorías que ayudaran a exponer y aclarar esta situación, categorías que resumimos en: de acuerdo con la ubicación precedente, se propone nueva delimitación, se define entorno y se añaden otros sitios a la delimitación.

Desgraciadamente, en varios casos no pudimos pronunciarnos, ni en éste ni en otro sentido, por motivos diversos: la Cueva de Pecho Redondo o de la Torrecilla, en Marbella, a la que no logramos llegar en las sucesivas visitas realizadas y cuyos restos pictóricos, a la luz de trabajos recientes, no parecen tener la trascendencia histórica que se les atribuyó inicialmente 10; la Cueva del Cantal Chico, en Rincón de la Victoria, conocida por las noticias de $\mathrm{H}$. Breuil "I, y que no ha vuelto a ser localizada; el Abrigo del Puerto del Viento, en Ronda, cuya calidad de lugar con arte rupestre sólo es citada M. Más Cornellá en su Catálogo... y que no pudimos localizar y, por último, los Abrigos I y 2 de la Sierra de Camarolos, en Villanueva del Rosario, que tampoco encontramos siguiendo la información de partida 12.

Tomo 3. Vol. II.

Memoria.

Es la síntesis del trabajo. En ella nos detenemos a comentar las particularidades geográicas de los territorios que albergan a estas cavidades, ofreciendo información de carácter general acerca del medio natural, de modo que el lector obtenga una idea aproximada del entorno en que se encuentran los yacimientos arqueológicos.

En el capítulo dedicado al análisis del estado actual de las estaciones con arte rupestre explicamos las diferentes circunstancias que sería preciso considerar a la hora de plantear las actuaciones necesarias para la correcta preservación de estos bienes culturales. Esta reflexión aborda los problemas desde una perspectiva global, tomando en consideración tanto las determinaciones urbanísticas y territoriales como el conjunto de factores, a veces difícilmente definibles y/o categorizables que son, en muchos casos, responsables directos de la situación en que se encuentran las estaciones con arte rupestre de la provincia de Málaga.

Para terminar, se reflejan en un gráfico las actuaciones que desde nuestro punto de vista podrían acometerse en cada uno de estos yacimientos. Aquí se tienen en cuenta todos los ámbitos de la Tutela, por lo que se plantean las siguientes acciones: Delimitación; Declaración como Zona Arqueológica B.I.C.; Cons- 
titución como Conjunto Arqueológico; Constitución como Unidad Básica; Vigilancia; Adquisición; Cerramiento; Enterrado; Restauración; Adecuación para su visita; Intervención arqueológica; Difusión.

Quizás debamos detenernos a comentar brevemente algunos de los términos empleados. Cuando decimos Declaración como Zona Arqueológica B.I.C. nos referimos a cualquiera de las figuras que contempla la legislación estatal y autonómica en este sentido. Cuando planteamos la posibilidad de adquirir algún sitio arqueológico no pensamos exclusivamente en la compra, sino más bien en todas aquellas acciones legales conducentes a que la propiedad conste y se reconozca como pública, porque hay casos donde sería conveniente completar expedientes en este sentido, determinando cuáles son los límites de la propiedad privada. También hay otros lugares donde, si llegaran a concretarse las actuaciones urbanísticas que se prevén, quizás fuera conveniente, por cuestiones de estrategia de la gestión, que los yacimientos formaran parte indiscutible del dominio público, administraciones municipales incluidas.

La prioridad de las intervenciones en cada yacimiento se expresa a partir de su propia distribución en el gráfico, donde se colocan las actuaciones de Protección, seguidas de las de Conservación e Investigación y Difusión. La dirección de las flechas indica el orden o la finalidad primordial de las actuaciones propuestas, y éstas sólo se refieren a la actividad indicada en los puntos de partida y llegada. Por ejemplo, para la Cueva de Los Chivos contamos con una delimitación precisa, pero considerando las dudas que suscita el origen de esas pinturas, así como la posible existencia de un yacimiento soterrado en el interior de la cavidad, es prioritario realizar una intervención arqueológica que determine la conveniencia de continuar el expediente de declaración como Zona Arqueológica B.I.C. en función de su pertenencia al conjunto de estaciones que contienen arte rupestre en Andalucía.

Los tomos 4, Documentación complementaria, y 5, Documentación cartográfica, incluyen información variada de gran relevancia para el trabajo. En el primero se reproducen los Títulos III y IV del Plan Especial de Protección del Medio Físico de la provincia de Málaga y las figuras de ordenación de los espacios naturales afectados; también se recoge íntegramente el Decreto de Regulación y Desarrollo de la figura de Monumento Natural de Andalucía, así como copias de expedientes de actuaciones de otras administraciones en el entorno de algunas estaciones con arte rupestre.

El tomo 5 contiene la documentación cartográfica que manejamos. Aunque fue de gran utilidad la planimetría que acompaña al Plan Especial de Protección del Medio Físico y la cartografía de los Parques Naturales no las incluimos porque sus dimensiones y escaso nivel de detalle dificultan la lectura; en todo caso, las normas urbanísticas asumen las determinaciones medioambientales y las reflejan sobre su planimetría. Sí se han incluido, sin embargo, copia de los planos del planeamiento urbanístico, de las delimitaciones de montes públicos y los planos catastrales de las parcelas afectadas por nuestra delimitación.

Fig. 3. Propuestas de actuación en las estaciones con arte rupestre de la provincia de Málaga (I).

\begin{tabular}{|c|c|c|c|c|c|c|c|c|c|c|c|}
\hline$M A L A G A$ & $\begin{array}{l}\text { AERTOOS } \\
\text { 1-2. TNOS } \\
\text { DEL VILO }\end{array}$ & 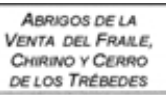 & $\begin{array}{l}\text { Cuevade } \\
\text { Las } \\
\text { CHNOS }\end{array}$ & $\begin{array}{l}\text { Cuevad DE } \\
\text { LAS } \\
\text { GRAAS }\end{array}$ & $\begin{array}{l}\text { AARISO OEL } \\
\text { CORNNO DE AA } \\
\text { ESCAROAOERA }\end{array}$ & 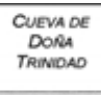 & $\begin{array}{l}\text { CuEVN ORL } \\
\text { TOAOOOOEL } \\
\text { CALAMORPO }\end{array}$ & $\begin{array}{l}\text { CuEva De } \\
\text { LA PIETA }\end{array}$ & $\begin{array}{c}\text { SIMAO OE } \\
\text { LA CORRPA } \\
\text { OOE LOS } \\
\text { MUACIELAGOS }\end{array}$ & $\begin{array}{c}\text { ABRroos of } \\
\text { PENAS OE } \\
\text { CMBRERA }\end{array}$ & $\begin{array}{l}\text { RaAADeL } \\
\text { RETUNTUN }\end{array}$ \\
\hline \multicolumn{12}{|l|}{ PROTECCION } \\
\hline \multicolumn{12}{|l|}{ DEUMTACION } \\
\hline \multicolumn{12}{|l|}{$\begin{array}{l}\text { ZONA ARQUEOLOGICA } \\
\text { B.I.C. }\end{array}$} \\
\hline \multicolumn{12}{|l|}{$\begin{array}{l}\text { CONJUNTO } \\
\text { ARQUEOLDANO }\end{array}$} \\
\hline \multicolumn{12}{|l|}{ UNIDNO BASICA } \\
\hline \multicolumn{12}{|l|}{ VIILANCIA } \\
\hline \multicolumn{12}{|l|}{ ADOUISTCION } \\
\hline \multicolumn{12}{|l|}{ CONSERVACION } \\
\hline \multicolumn{12}{|l|}{ CERramiento } \\
\hline \multicolumn{12}{|l|}{ ENTERRADO } \\
\hline \multicolumn{12}{|l|}{ Restauracion } \\
\hline \multicolumn{12}{|l|}{ ADECUACION } \\
\hline \multicolumn{12}{|l|}{ INVESTIGACION } \\
\hline \multicolumn{12}{|l|}{ 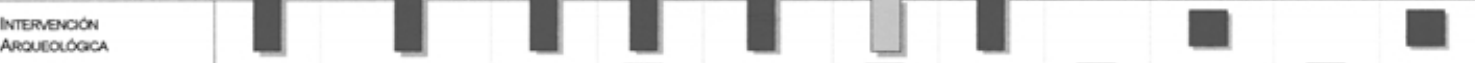 } \\
\hline Drustón & & & & & & & & & & & \\
\hline
\end{tabular}


Fig. 3. Propuestas de actuación en las estaciones con arte rupestre de la provincia de Málaga (li).

\begin{tabular}{|c|c|c|c|c|c|c|c|c|c|c|c|}
\hline$M A L A G A$ & $\begin{array}{l}\text { Cueva } \\
\text { NAVAPPOO }\end{array}$ & $\begin{array}{c}\text { CERPO } \\
\text { DELA } \\
\text { TORTUGA }\end{array}$ & $\begin{array}{l}\text { CUEVADOE } \\
\text { PECHO } \\
\text { REDONDO }\end{array}$ & $\begin{array}{c}\text { CUEVA } \\
\text { OELLS } \\
\text { PORQUEROS }\end{array}$ & 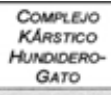 & $\begin{array}{c}\text { CUEVA DE } \\
\text { NEAJA }\end{array}$ & $\begin{array}{c}\text { ABRNOOODE } \\
\text { MARCHANONAS }\end{array}$ & 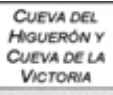 & $\begin{array}{l}\text { ABRNOOODEL } \\
\text { PUERTO DEL } \\
\text { VIENTO }\end{array}$ & $\begin{array}{l}\text { CUEVA DEL } \\
\text { TANO OEL } \\
\text { MOUINO }\end{array}$ & 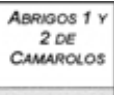 \\
\hline \multicolumn{12}{|l|}{ PROTECCION } \\
\hline \multicolumn{12}{|l|}{ Deumitacion } \\
\hline \multicolumn{12}{|l|}{$\begin{array}{l}\text { ZONA AROUEOLDICA } \\
\text { B.LC. }\end{array}$} \\
\hline \multicolumn{12}{|l|}{$\begin{array}{l}\text { CONJUNTO } \\
\text { ARQUEOLOGNCO }\end{array}$} \\
\hline \multicolumn{12}{|l|}{ UNIDAO BASICA } \\
\hline \multicolumn{12}{|l|}{ VIOLANCIA } \\
\hline \multicolumn{12}{|l|}{ ADOUISICION } \\
\hline \multicolumn{12}{|l|}{ CONSERVACION } \\
\hline \multicolumn{12}{|l|}{ Cerramiento } \\
\hline \multicolumn{12}{|l|}{ ENTERRADO } \\
\hline \multicolumn{12}{|l|}{ REstauración } \\
\hline \multicolumn{12}{|l|}{ ADECUACION } \\
\hline \multicolumn{12}{|l|}{ INVESTIGACION } \\
\hline \multicolumn{12}{|l|}{ 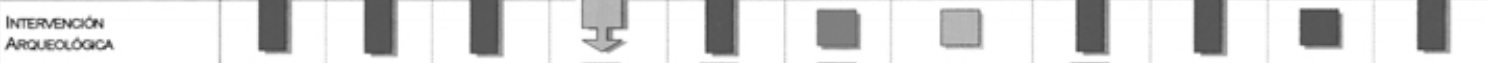 } \\
\hline DAfusion & & & & & & & & & & & \\
\hline REAUZAOD & Unceent & & OPUZO & & & & & & & & \\
\hline & & & 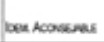 & & Nepossar & $\cos x+\infty$ & & & & & \\
\hline
\end{tabular}

Dicho esto, comentaremos los resultados del trabajo en la Cueva de Doña Trinidad (Ardales), buen exponente de las distintas problemáticas que advertimos en las estaciones malagueñas y un enclave arqueológico y geológico de primera magnitud, propiedad de la Junta de Andalucía 13.

La Cueva de Doña Trinidad o de Ardales es uno de los grandes santuarios del arte parietal pleistocénico, no sólo de Andalucía sino de la Península Ibérica. Su enorme interés desde el punto de vista histórico-arqueológico radica en el gran número y variedad temática y técnica de las pinturas y grabados, realizados durante el Paleolítico Superior, que han pervivido en las paredes y el suelo de la gruta. Además, las galerías altas conservan, junto a un santuario monotemático de figuras negras, quizá Solutrense, restos de estructuras de habitación y enterramientos de inhumación postpaleolíticos ${ }^{14}$. Podemos concluir, pues, que la cueva estuvo ocupada en diferentes momentos de la Prehistoria, quizás con fines diversos: habitación, santuario, enterramiento... Desde el punto de vista de su geomorfología la cavidad consta de tres partes: Galerías Bajas, Galerías Altas y Sala del Colapso, y aunque actualmente sólo posee una boca de entrada se han detectado otras dos paleobocas -en las Galerías Altas y en la Galería del Lago-, taponadas por un relleno de arcillas y bloques 15 .

Según consta en el Catastro de Rústica de la Provincia de Málaga, la Cueva de Doña Trinidad es propiedad de la Junta de Andalucía. En ella el Ayuntamiento de Ardales promueve, desde hace más de diez años, la realización de trabajos de investigación y conservación cuyos resultados se han ido publicando paulatinamente por el propio Ayuntamiento o sus autores en revistas científicas y de divulgación. En esta línea de actuaciones se llevó a cabo el cierre de una de las bocas de la cavidad con una puerta blindada cubierta con una estructura escalonada que culmina en una plataforma a modo de mirador. Dicha intervención no consiguió eliminar el riesgo de acceso incontrolado, toda vez que se conocen al menos otras dos antiguas bocas por las que, con ciertas dificultades, se podría acceder al interior la cueva. En las mismas fechas se reparó un tramo del camino y se abrió otro nuevo para llegar en automóvil hasta el acceso actual, allanándose una zona para aparcamiento. Estas intervenciones iban encaminadas a la explotación turística de la cueva, que ya había puesto en práctica a principios de siglo su antigua propietaria, Dña. Trinidad Gründ, y que la Corporación Municipal ha retomado de un modo más racional, estableciendo un horario de visitas, guiadas, y limitando el número de visitantes, así como el acceso a determinadas zonas. Actualmente la Cueva de Ardales, que poco a poco va perdiendo su denominación inicial -Cueva de Doña Trinidad- aparece en folletos y propagandas turísticas sobre esta zona, comercializada bajo la denominación Embalse del Guadalteba.

En cuanto a medidas de protección administrativas, cuando realizamos el trabajo aún no se había iniciado el expediente para completar la declaración legal genérica como Bien de Interés Cultural que le otorga la Ley 16/1985 PHE. En cuanto a la protección del medio natural, la cavidad se encuentra dentro del Espa- 
cio Forestal de Interés Recreativo Sierra de La Pizarra, que recoge el Plan Especial de Protección del Medio Físico destacando su notable interés paisajístico y faunístico, advirtiendo que podrían verse deteriorados por la presión de los numerosos visitantes que frecuentan la zona. El documento, a la vista de la complejidad de los usos que se dan en este espacio, principalmente de los destinados al ocio y explotación turística, recoge en su programa de actuación la conveniencia de redactar el Plan Especial Sierra de La Pizarra-El Chorro, y recomienda que se cree una Comisión Gestora, formada por los organismos afectados, para coordinar la protección del medio natural con los posibles usos sociales.

Por su parte, las Normas Subsidiarias de Ardales cuentan con una normativa general de protección arqueológica que asigna el mayor grado de protección a los yacimientos ... declarados Monumento HistóricoArtístico de carácter nacional por Decreto-Ley, caso de la Cueva de Doña Trinidad, prohibiendo toda operación de desarrollo, excepto obras de mejora de accesos, sujetas a informe previo, y la reconstrucción y excavación autorizadas por el Organismo competente y dirigidas por personal cualificado. Se permiten usos recreativos y agrícolas, con labores únicamente superficiales y siempre que se demuestre que no causarán daño al yacimiento arqueológico. Por último, se propone el cerramiento de la cavidad, su excavación arqueológica y, si fuera necesario, medidas de consolidación. Sin embargo, en ningún caso se regula la participación de la Consejería de Cultura en la concesión de licencias para las actividades a desarrollar sobre áreas de protección arqueológica; no se concretan usos prohibidos, autorizables o permitidos; ni tampoco se definen con claridad los límites del polígono de protección, donde se incluía una necrópolis de cistas, a la que se asigna un grado de protección inferior al de la propia cueva ${ }^{16}$.

Una vez contrastadas las determinaciones del planeamiento urbanístico con las especificidades del yacimiento arqueológico, propusimos una nueva delimitación gráfica, así como una serie de medidas

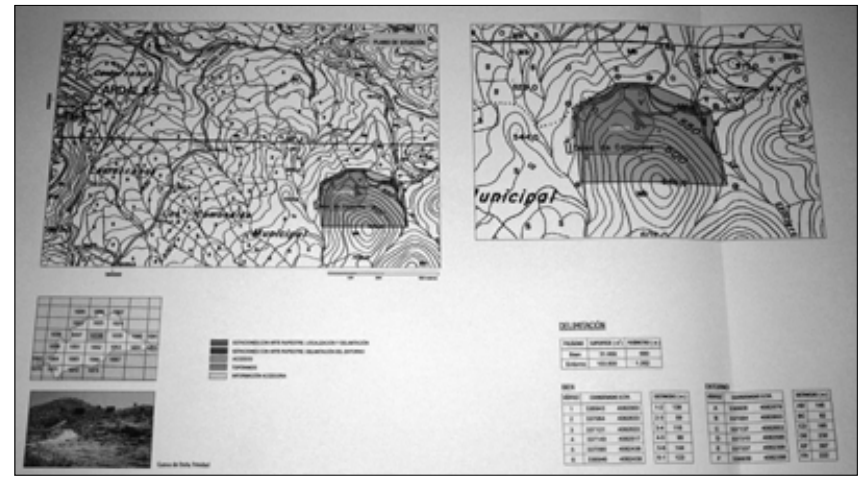

protectoras particulares para la Cueva de Doña Trinidad. Dichas medidas se basan en la condición de Bien de Interés Cultural que le confiere el art. 40.2 de la Ley 16/1.985 PHE, lo cual obliga al municipio a redactar un Plan Especial de Protección, u otro de los instrumentos de planeamiento previstos en la legislación urbanística, que cumpla las exigencias establecidas por la Ley en el área afectada por la declaración 17. El marco legal permite, en consecuencia, una amplia gama de posibilidades sobre la selección del tipo de planeamiento, siendo opciones tan válidas la redacción de un Plan Especial como la asunción de contenidos de protección por el planeamiento general.

Así definimos, como territorio a proteger desde las Normas Subsidiarias de Ardales, la ladera Norte del cerro de la Calinoria, en cuya base se encuentra la cueva (Figura 4); a este ámbito se le otorga un tratamiento de protección específico, concretado en unos contenidos particulares a asumir por el planeamiento, al menos mientras no se defina la figura de protección legal y se plasme en su correspondiente expediente, que a mi entender debería ser una declaración como Zona Arqueológica Bien de Interés Cultural. Nuestra propuesta consistió en:

A. delimitar un área de protección para la Zona Arqueológica B.I.C. Cueva de Doña Trinidad ordenando usos prohibidos, usos sometidos a autorización administrativa y usos permitidos, como sigue:

\section{Usos Prohibidos \\ En general, cualquier obra o actividad que pueda afectar las labo- res de protección, investigación y conservación del yacimiento arqueológico.}

Explanaciones y aterrazamientos $y$, en general, movimientos de tierra de cualquier naturaleza, excepto los directamente relacionados con la investigación científica de los yacimientos.

Obras destinadas a la captación de agua.

Implantación de cultivos cuyo laboreo implique remociones del terreno.

Tala de árboles a efectos de transformación del uso del suelo.

Paso de maquinaria agrícola o de cualquier otra tipología o uso, con especial prohibición sobre la de gran tonelaje.

Extracciones de arena y áridos, explotaciones mineras a cielo abierto y las instalaciones e infraestructuras vinculadas al desarrollo de este tipo de actividades.
Propuesta de delimitación de bien y entorno. Cueva de Doña Trinidad, Ardales.
Instalación de soportes de publicidad o elementos análogos, excepto los de carácter institucional que proporcionen información sobre el espacio objeto de protección y no supongan deterioro del paisaje.

Localización de vertederos de residuos de cualquier naturaleza.

Todo tipo de obras de carácter infraestructural, así como anejas, sean temporales o no.

Obras e instalaciones turístico-recreativas, parques de atracciones y construcciones hosteleras.

Construcciones residenciales en cualquiera de sus supuestos o modalidades.

Construcción o instalación de obras relacionadas con la explotación de recursos vivos, incluyendo instalaciones de primera transformación e invernaderos, establos, piscifactorías, infraestructuras vinculadas a la explotación, etc. 


\section{Usos Prohibidos}

Construcciones e instalaciones vinculadas a la ejecución, entretenimiento y servicio de las obras públicas.

Construcciones que guarden relación con la naturaleza de la finca

Construcciones y edificaciones industriales de todo tipo.
Construcciones y edificaciones públicas singulares.

Construcciones e instalaciones de utilidad pública o interés social que deban emplazarse en el medio rural.

\section{Usos Permitidos}

Caza, en períodos autorizados, con información expresa acerca de la prohibición de establecer puestos de caza, cobertizos o cualquier otra instalación relacionada con la actividad en el área delimitada.

Reparación de vallados, siempre y cuando se desarrolle por el mismo trazado y se utilicen las mismas técnicas de sujección.

Visitas, en el régimen establecido por la Ley para este tipo de bienes culturales.

\section{Usos sometidos a Autorización Administrativa}

Las instalaciones que, contempladas en un proyecto unitario, se destinen a mostrar o exponer las características del yacimiento, previa autorización e informe del organismo competente.

Actividades orientadas a potenciar los valores del yacimiento arqueológico: actuaciones de investigación, conservación, protección, etc.
Adecuaciones de carácter ecológico, recreativo o de otra índole, tales como creación de parques, rutas turístico-ecológicas, instalaciones deportivas en medio rural, etc.

Obras de acondicionamiento, mejora y reparación de caminos y accesos consolidados.

Tareas de restauración ambiental.
B. definir, sobre la delimitación anterior, un entorno de protección que englobe el acceso al enclave arqueológico, donde igualmente unas normas específi- cas ordenen los usos prohibidos, sometidos a autorización administrativa y permitidos como sigue:

\section{Usos Prohibidos}

En general, cualquier obra o actividad que altere cualitativamente los valores arqueológicos y ambientales que definen el entorno de protección y que no cuente con las autorizaciones administrativas de carácter sectorial.

Explanaciones y aterrazamientos $y$, en general, movimientos de tierra de cualquier naturaleza, excepto los directamente relacionados con la investigación científica del yacimiento.

Obras destinadas a la captación de agua.

Tala de árboles a efectos de transformación del uso del suelo.

Extracciones de arena y áridos, explotaciones mineras a cielo abierto y las instalaciones e infraestructuras vinculadas al desarrollo de este tipo de actividades.

Instalación de soportes de publicidad o elementos análogos, ex-

cepto los de carácter institucional que ofrezcan información sobre el espacio objeto de protección y no supongan deterioro del paisaje.

Localización de vertederos de residuos de cualquier naturaleza.

Construcciones residenciales en cualquiera de sus supuestos o modalidades.

Construcción o instalación de obras relacionadas con la explotación de recursos vivos, incluyendo instalaciones de primera transformación, inverna-deros, establos, piscifactorías, infraestructuras vinculadas a la explotación, etc.

Instalación de campamentos de turismo y campamentos públicos y sociales.

Construcciones y edificaciones industriales.

\section{Usos Permitidos}

Reparaciones de carácter superficial, es decir, que no conlleven alteraciones del subsuelo.

Caza, en períodos autorizados, informando expresa-mente sobre la prohibición de establecer puestos de caza, cobertizos o cualquier instalación en el área delimitada como entorno del bien.

\section{Usos sometidos a Autorización Administrativa}

Con carácter general, aquellas actuaciones que requieran concesión de licencia urbanística.

Las instalaciones que, contempladas en un proyecto unitario, estén orientadas a mostrar o exponer las características de los yacimientos.

Adecuaciones de carácter ecológico, recreativo o de cualquier otra índole, tales como creación de parques, rutas turístico-ecológicas, instalaciones deportivas en medio rural, etc.

Tareas de restauración ambiental.

Obras de acondicionamiento, mejora y reparación de caminos y accesos consolidados.

Construcciones y usos destinados a la hostelería y el esparcimiento, incluidas las instalaciones no permanentes y de carácter desmontable.
Construcción/instalación de señalética, imágenes o símbolos monumentales o conmemorativos.

Construcciones e instalaciones vinculadas a la ejecución, entretenimiento y servicio de las obras públicas.

Construcciones e instalaciones de utilidad pública o interés social que deban emplazarse en medio rural.

Construcciones que guarden relación con la naturaleza de la finca. Cambios de cultivos.

Desarrollo de infraestructuras de cualquier clase, así como instalaciones y edificaciones necesarias para su mantenimiento. 
Complementamos nuestra propuesta con unas normas de tramitación y autorización destinadas a regular las actividades sobre las estaciones con arte rupestre, y que han sido las mismas para toda la provincia de Málaga. En ellas establecimos las obligaciones de los propietarios o promotores que pretendan llevar a cabo una actividad en los ámbitos de protección de las Zonas Arqueológicas delimitadas por nosotros; el procedimiento para la obtención de autorización y licencia; las obligaciones de propietarios y titulares; la realización de consultas y, por último, las infracciones.

Recapitulando, creímos importante aprovechar la oportunidad que ofrece la revisión de las Normas Subsidiarias para sugerir a la Consejería de Cultura que informara el documento de Avance como se ha expuesto. Pero, independientemente de la asunción de medidas de protección específicas en el planeamiento urbanístico, creemos que un yacimiento arqueológico de tal entidad histórica, cultural y, por añadidura, patrimonial, debería gozar de un expediente de Declaración como Zona Arqueológica B.I.C. Para ello aconsejamos realizar una prospección arqueológica superficial intensiva de la zona inmediata a la cueva en un área que, hacia el Sur, llegue hasta el límite del Término Municipal; hacia el Este, hasta el Arroyo de La Escalera; al Norte, hasta el camino de la Casa de Calinoria; y al Oeste, siguiendo la cota más baja del cerro de La Calinoria, donde se encuentra la caverna, que baje hasta el límite del Término Municipal por el sur. Basamos esta propuesta en la notable concentración de yacimientos arqueológicos prehistóricos que las prospecciones superficiales llevadas a cabo en los años 80 han puesto de manifiesto para esta área, donde se han detectado un taller lítico y una necrópolis de cistas, además de la ocupación postpaleolítica de las Galerías Altas en la propia Cueva de Doña Trinidad ${ }^{18}$
Tal complejidad de usos históricos sobre el territorio es conveniente que se viera reflejada también en el documento de protección mediante la delimitación de diferentes áreas de afección, y por lo tanto de protección, en el entorno de la cavidad. De hecho, las Normas Subsidiarias en vigor apuestan por una delimitación amplia para el yacimiento, donde se incluye una necrópolis de cistas situada al Sur de la caverna. Mientras todo esto sucede, optamos por ofrecer al planeamiento una delimitación más restringida porque con los datos derivados de las investigaciones realizadas no es posible precisar áreas concretas que garanticen la protección de yacimientos arqueológicos de los que no conocemos siquiera su extensión aproximada. De ahí la necesidad de completar el expediente de declaración como Zona Arqueológica B.I.C. tras una actuación arqueológica basada en el análisis exhaustivo de un ámbito territorial nunca menor del que más arriba reseñamos.

Por otra parte, a la hora de valorar los factores de riesgo contábamos con que en los últimos años se llevaron a cabo diversos trabajos de investigación, preservación y difusión del yacimiento, y sus resultados permitieron aquilatar, con mayor precisión que en otros casos, la incidencia de aquellos. Así, tratándose de una cavidad muy estable geomorfológica y geológicamente, los factores climatológicos no parecen determinantes para la correcta conservación del yacimiento arqueológico. Mas aunque en el curso de las actuaciones comentadas se tomaron las medidas de preservación antes reseñadas -cierre de un acceso, horario y limitación del número de visitas, etc...todavía podríamos indicar otras cuestiones que siguen representando un grave riesgo: no se han cerrado otros accesos; no se ha planteado un proyecto sistemático de limpieza, consolidación, reproducción y conservación de pinturas y grabados, ni de investigación del interesantísimo yacimiento arqueológico de las Galerías Altas. (Fig. 5)

Fig. 5. Evaluación de factores de riesgo.

CUEVA DE DOÑA TRINIDAD

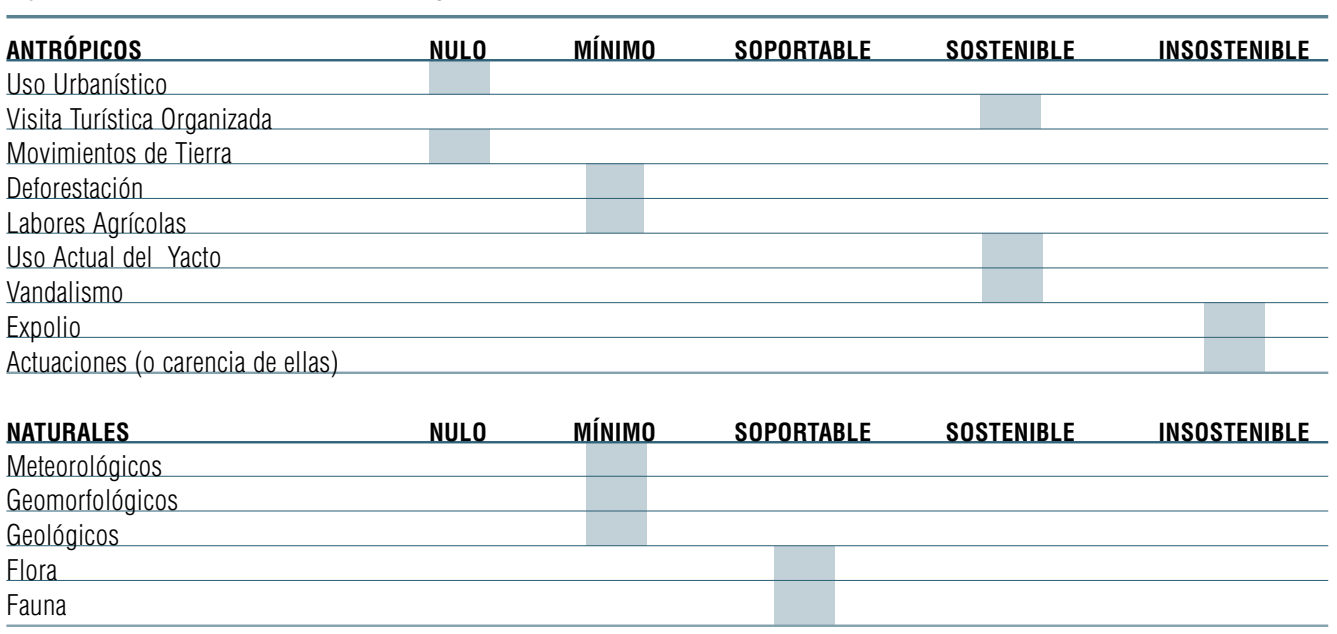


En estas circunstancias, propusimos a la Consejería de Cultura que estudiara la posibilidad de adoptar las medidas necesarias para establecer el horario de visitas más adecuado a las condiciones del complejo cárstico -el cual debería tener, quizás, carácter estacional-, así como para determinar, tras valorar el estado de conservación de pinturas y grabados y del yacimiento arqueológico, las salas que puedan abrirse al público y el número de visitantes a recibir por jornada. Estas actuaciones no se dirigen sólo a la mejor conservación del yacimiento arqueológico sino también de la caverna, y deberían adoptarse tras realizar investigaciones geológicas que analicen la incidencia de la explotación turística en el medio ambiente de la cavidad y, por consiguiente, en la correcta conservación de las representaciones artísticas, porque los resultados de los estudios realizados en este sentido por el Ayuntamiento de Ardales sólo han sido parcialmente publicados 19. Tan ambicioso proyecto debía promoverse simultáneamente por la Consejería de Cultura y las restantes Administraciones que intervienen en la protección y gestión del territorio, y sus resultados podrían desarrollarse a través de un Plan Especial Rector de Uso y Gestión que ordenara los usos y actividades realizables sobre este Bien de Interés Cultural.
I. Participaron en la realización del trabajo J. M. Pérez Mazón y A. Pérez Paz.

2. No queremos olvidar la ayuda prestada por algunos compañeros de la Consejería de Cultura tanto a través de las sucesivas reuniones de seguimiento del trabajo como siempre que solicitamos su opinión, principalmente del Jefe de Servicio de Protección de la Dirección General de Bienes Culturales, Juan Manuel Becerra, y de la Arqueóloga Sandra Rodríguez de Guzmán, del Departamento de Régimen Especial del citado Servicio, cuyas aportaciones sin duda han enriquecido los resultados de este trabajo. Nuestro agradecimiento también a la buena predisposición hacia el trabajo que siempre mostraron Miguel Baturone, Jefe de Departamento de Régimen Especial, y Pilar Hurtado, Geógrafa del mismo Departamento.

3. En otra publicación se presenta el documento Delimitación de áreas con riesoo de destrucción en las estaciones con arte rupestre de Andalucía. Málaga, explicando con detalle los requerimientos de la Dirección General de Bienes Culturales con respecto a este trabajo: Santana Falcón, l. y Rodríguez de Guzmán, S.: "Actuaciones en materia de protección en los enclaves con manifestaciones artísticas rupestres en Andalucía", en prensa.

4. M. VIVAS, V. E.: "Las manifestaciones pictóricas del abrigo Cortijo de La Escardadera", Zephyrus, XLIV-XLV, 1991-1992.

5. MÁS CORNELLÁ, M.: Catálogo de yacimientos con pinturas rupestres en Andalucía, Consejería de Cultura, 1995, inédito.

6. Ibid. nota 4.

7. Ibid. nota 5 y SANCHIDRIÁN TORTI, J. L.: Catálogo provincial del arte rupestre prehistórico de Málaga, Consejería de Cultura, inédito.

8. SANCHIDRIÁN TORTI, J. L.: "Aportaciones al acervo artístico esquemático de la provincia de Málaga", Actas del XV C.N.A., Zaragoza, 1987. También V. E. M. Vivas en el trabajo citado en la nota 4

9. Confróntese SANCHIDRIÁN TORTI, J. L.: Catálogo provincial del arte rupestre prehistórico de Málaga, Consejería de Cultura, inédito.
10. SANCHIDRIÁN TORTI, J. L.: Catálogo provincial del arte rupestre prehistórico de Málaga, Consejería de Cultura, inédito.

I I. BREUIL, H. et al: Rock paintings of Southern Andalusia. A description of a Neolithic and Copper Age art group, Oxford, 1929.

12. Ibid. nota 8.

13. El trabajo citado en la nota 3 lo dedicamos al Conjunto Rupestre de las Peñas de Cabrera (Casabermeja), constituido por veinte y tres abrigos con pinturas rupestres postpaleolíticas, también propiedad de la Junta de Andalucía. Con ambos ejemplos creemos haber aportado una visión general de la problemática de estos yacimientos arqueológicos en la provincia de Málaga.

14. RAMOS MUÑOZ, J. et al.: Cueva de Ardales. Su recuperación y estudio, Ayuntamiento de la Villa de Ardales, Ardales, 1992.

15. En el formulario 8.2 del Catálogo de Estaciones con Arte Rupestre en Andalucía (en adelante C.E.A.R.A.) se describe la morfología de la cueva, la temática de sus pinturas y grabados y los otros hallazgos. Para mayor precisión puede consultarse la bibliografía recogida en el formulario $8.3 \mathrm{del}$ C.E.A.R.A. y especialmente el trabajo citado antes.

16. Debemos advertir que las Normas Subsidiarias de Ardales están siendo revisadas actualmente, y que nosotros trabajamos sobre el documento en vigor, por lo que quizás algunos aspectos que aquí se comentan estén siendo ahora modificados

17. Título II, De los Bienes Inmuebles, artículo 20 de la Ley 16/1985 de 25 de junio del P.H.E.

18. Véase ESPEJO HERRERÍAS, Ma M. et al.: "Informe sobre las prospecciones arqueológicas realizadas en el valle del río Turón (Casarabonela-El Burgo). Año 1989", A.A.A., 1989, II, 1991. También RAMOS MUÑOZ, J. et al., 1992.

19. Véase RAMOS MUÑOZ, J. et al., 1992, págs. 5-6. 